\title{
Microstructure of Surface and Subsurface Layers of a Ni-Ti Shape Memory Microwire
}

\author{
H. Tian, ${ }^{1}$ D. Schryvers, ${ }^{1, \star}$ S. Shabalovskaya, ${ }^{2, \dagger}$ and J. Van Humbeeck ${ }^{2}$ \\ ${ }^{1}$ EMAT, University of Antwerp, Groenenborgerlaan 171, B-2020 Antwerp, Belgium \\ ${ }^{2}$ MTM, K.U. Leuven, Kasteelpark Arenberg, B-3001 Leuven, Belgium
}

\begin{abstract}
The microstructure of a $55 \mu \mathrm{m}$ diameter, cold-worked Ni-Ti microwire is investigated by different transmission electron microscopy techniques. The surface consists of a few hundred nanometer thick oxide layer composed of $\mathrm{TiO}$ and $\mathrm{TiO}_{2}$ with a small fraction of inhomogeneously distributed $\mathrm{Ni}$. The interior of the wire has a core-shell structure with primarily B2 grains in the $1 \mu \mathrm{m}$ thick shell, and heavily twinned B19' martensite in the core. This core-shell structure can be explained by a concentration gradient of the alloying elements resulting in a structure separation due to the strong temperature dependence of the martensitic start temperature. Moreover, in between the $\mathrm{B} 2$ part of the metallic core-shell and the oxide layer, a $\mathrm{Ni}_{3} \mathrm{Ti}_{\text {interfacial }}$ layer is detected.
\end{abstract}

Key words: nickel-titanium microwire, TEM, shape memory, surface modification, composition gradient, surface oxide, rutile, Ni release, EELS

\section{INTRODUCTION}

Due to its unique mechanical properties including shape memory and superelasticity, its durability and biocompatibility, applications of Nitinol for a wide variety of medical implants and devices are progressively increasing (Ryhänen, 1999; Shabalovskaya, 2001, 2002; Kujala et al., 2004). However, as Nitinol consists of about 50 at.\% Ni, certain applications are still hindered by the concern of $\mathrm{Ni}$ release in the surrounding tissue. The biocompatibility of $\mathrm{Ni}$-Ti implants is essentially guaranteed by a corrosion resistant and biologically inert titanium oxide layer avoiding severe toxicological and allergic responses to the Ni (Shabalovskaya, 1996). The structure of this layer can be controlled by various thermomechanical surface treatments (Shabalovskaya, 1996, 2002). Due to the present day miniaturization of Nitinol devices, concerns with their corrosion and fracture, and especially Ni release in the body, are worsening. Although the titanium oxide layer is formed spontaneously on the Nitinol surface, reports on the increase of Ni release with time (up to 6 months) are multiplying (Cisse et al., 2002; Kobayashi et al., 2005; Clarke et al., 2006; Sui \& Cai, 2006). These new patterns in Ni release are different from those observed traditionally when the release was reduced to undetectable levels after 10-14 days of exposure of Nitinol

Received February 25, 2008; accepted August 21, 2008

*Corresponding author. E-mail: nick.schryvers@ua.ac.be

†On leave from Ames Laboratory-DOE, Ames, IA 50011, USA
(Wever et al., 1998; Michiardi et al., 2006; Ryhänen et al., 1997). For the moment there is no explanation for the controversies in the behavior of $\mathrm{Ni}$ release. However, $\mathrm{Ni}$ release that may be extended to a few months in the body would significantly alter the healing patterns of tissues surrounding the Ni-Ti implants. The unexplained cases of abnormal bone remodeling (Berger-Gorbet et al., 1996; Takeshita et al., 1997) and the problem with neointimal proliferation (Bayer \& Roguin, 1997; Roguin et al., 1999; Kobayashi et al., 2001) a few months after Nitinol implantation could easily be attributed to a lasting Ni release.

Although there are a number of studies on the chemistry and structure of surface sublayers of Nitinol that underwent various heat treatments, the exact mechanisms of formation of various $\mathrm{Ni}_{x} \mathrm{Ti}_{y}$ phases and types of metal diffusion in the surface and interior are not clear. This is especially true when considering Nitinol treated in various media and temperatures. The goal of the present study is to evaluate surface conditions of a Nitinol microwire produced by cold-work assisted by intermediate annealings, the expected materials starting condition for most applications of these wires. This is the first study in a series supported by focused ion beam (FIB) thinning to shed light on the troubling issues associated with the $\mathrm{Ni}$ accumulation on the surface and related $\mathrm{Ni}$ release. The microstructure of the surface and interior of the microwire are investigated by different transmission electron microscopy (TEM) techniques. The TEM sample preparation via FIB technique allows us to characterize both the near surface as well as the interior bulk structure in a systematic way. 

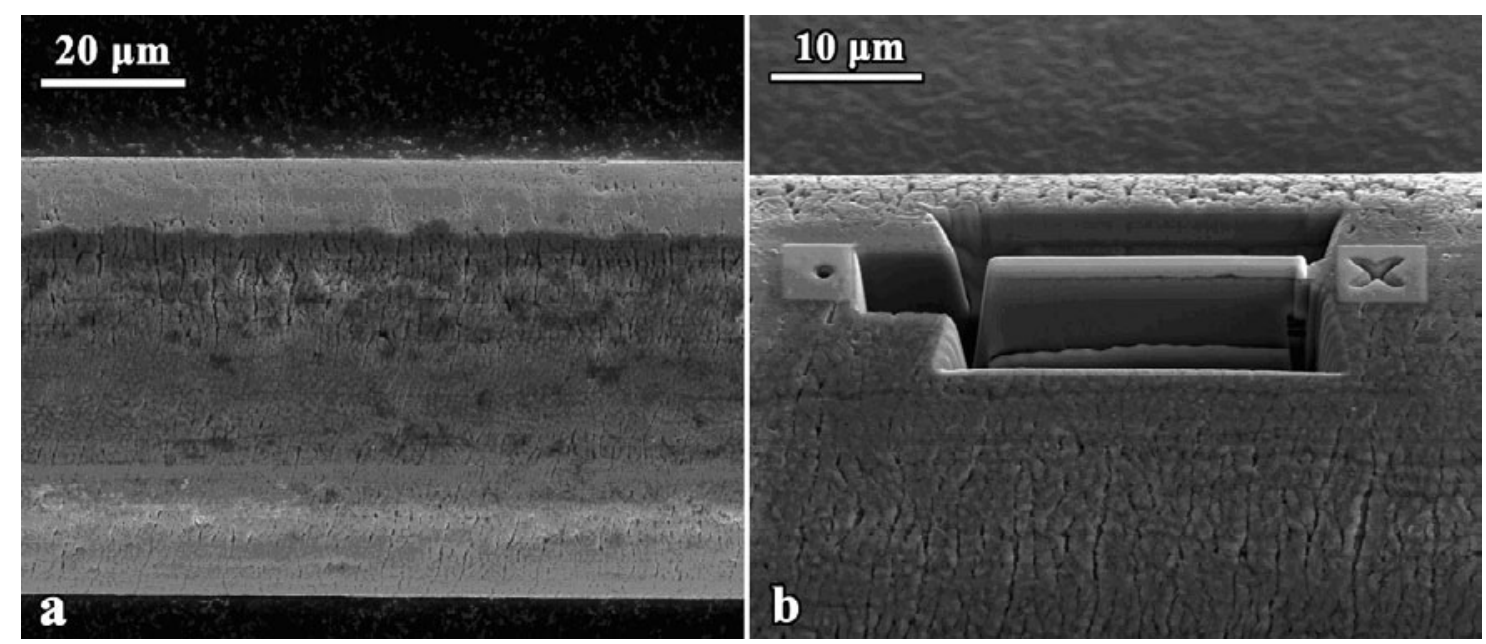

Figure 1. a: SEM image of the wire taken in a dual-beam FIB. b: TEM cross section manufactured by FIB at the surface of microwire

\section{Materials And Methods}

The $55 \mu \mathrm{m}$ diameter wire, purchased from Memory Metalle (Germany), is 30\% cold-worked after wire drawing and has a nominal composition of 49.48 at.\% Ni-50.52 at.\% Ti. Its fracture stress is $1,360 \mathrm{MPa}$ while the fracture strain is about $4 \%$. No phase transformation is observed by DSC when heating and cooling between $-50^{\circ} \mathrm{C}$ and $+150^{\circ} \mathrm{C}$.

Conventionally, metallic samples for TEM are prepared by electropolishing or occasionally by ion milling thin slice cuts from the bulk metal. However, in the present case of a wire with a diameter of only $55 \mu \mathrm{m}$, as shown in the scanning electron microscope (SEM) image of Figure 1a, these conventional techniques are hard to apply, plus they will destroy any site-specific information. Thus, an FEI FIB/SEM xT Nova Nanolab 200 was employed, which combines an SEM with a $\mathrm{Ga}^{+}$ion beam etching column. With this instrument, site-specific TEM samples from micronsized areas as required in the present case can be obtained.

TEM specimens were prepared following the in situ lift-out method by removing material from both sides of the desired cross section, as shown in Figure 1b (in the present article only results from cuts parallel to the long axis of the wire are presented). To prevent damaging the surface with the $\mathrm{Ga}^{+}$ions, the area of interest is covered in situ with a protective platinum layer prior to FIB cutting, which can be recognized as the smooth white-grey layer on top of the central cut in Figure 1b. After cutting, the slice of $\sim 15 \mu \mathrm{m}$ wide, $5 \mu \mathrm{m}$ deep, and $200 \mathrm{~nm}$ thick is cut free, fastened to a needle with Pt deposition and transported and fastened to a modified TEM grid. For regular cutting and thinning, the $\mathrm{Ga}^{+}$ions are accelerated by $30 \mathrm{kV}$; while for final thinning to electron transparency $(60 \mathrm{~nm})$, the accelerating voltage is reduced to $5 \mathrm{kV}$. By adjusting the angle of the incident ion beam, a large-scale $(3-5 \mu \mathrm{m})$ uniformly thin region can be achieved. Alternatively, after fine polishing, some parts of the specimen can be thinned enough $(<20 \mathrm{~nm})$ to allow high-resolution (HR) TEM imaging. Unfortunately, despite the use of relatively low voltages during the final thinning steps, the $\mathrm{Ga}^{+}$ion beam still introduces some local damage of the sample, especially at boundaries and interfaces as observed in some of the HRTEM images.

By using the site specificity of the FIB method, samples containing the oxide layer plus the first few microns of the $\mathrm{Ni}$-Ti material (as in Fig. 1b) have been prepared. Also samples from the interior of the wire have been made by first cutting the wire at an inclined angle with a sharp metal knife creating an inclined free surface with exposed interior material. FIB samples are then produced along this freshly inclined surface perpendicular to the central axis of the wire at different depths of the wire.

The TEM observations and energy dispersive X-ray (EDX) measurements were performed in a CM20 Philips instrument equipped with a thin window INCA $\mathrm{x}$-sight EDX detector. HRTEM images and electron energy-loss spectroscopy (EELS) studies were performed in an UltraTwin CM30 Philips FEG instrument equipped with a postcolumn GIF200 detector. EDX quantification was done with the company-provided Cliff-Lorimer thin ratio section software (INCA) in which absorption and fluorescence were ignored under the assumption of a thin foil. EELS quantification was performed in Digital Micrograph ${ }^{\circledR}$ via a sequence of background removals to separate the elementspecific excitation from the nonspecific background, multiple scattering removal by deconvolution with the zero-loss (ZL) spectrum, and conversion to chemical concentrations by using the appropriate single-scattering ionization cross sections. To improve the precision and spatial localization, the EELS analysis was performed in diffraction mode using 5-10 nm probes providing a relatively large amount of counts. For each new spectrum from a different region, a 

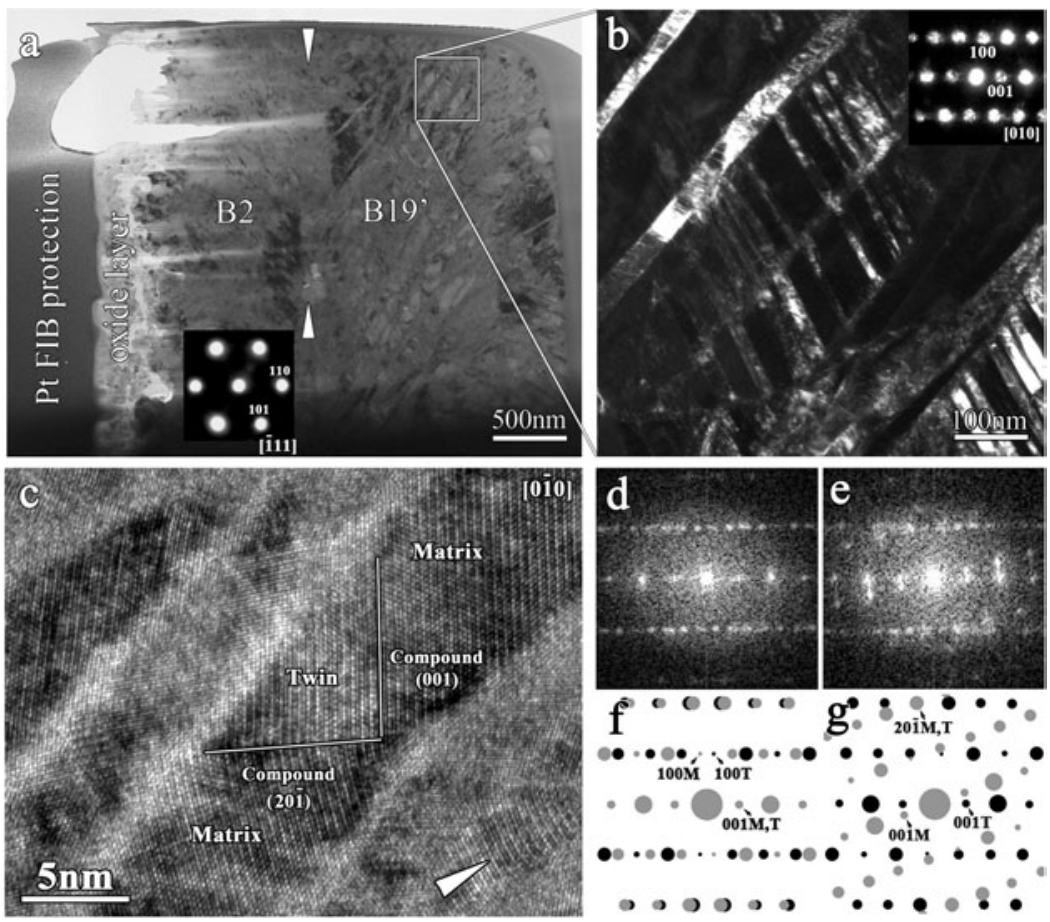

Figure 2. (a) Bright field image of both the near-surface oxide and bulk of a microwire, (b) dark-field image corresponding to the square area in a (nanoprobe electron diffraction patterns of B2 [111] zone axis and martensite B19' [010] zone axis are inserted in $\mathbf{a}$ and $\mathbf{b}$, respectively). (c) HRTEM of nanoscale twin structures of B19' martensite in the core. FFTs of (d) compound (001) and (e) (201) twins in c (location as labeled on HRTEM). The simulated diffraction patterns based on twinning modes of $\mathbf{f}$ compound (001) and $\mathbf{g}(20 \overline{1})$ twins. separate ZL was recorded, both with a dispersion of 0.20 $\mathrm{eV} /$ pixel. In some cases the details of the energy-loss-nearedge-structure (ELNES) are used to discriminate between similar compounds, in which cases a dispersion of 0.05 $\mathrm{eV} /$ pixel was used.

\section{Results}

\section{TEM Overview}

In Figure 2a both the surface oxide and the first few microns of the bulk of the microwire are recognized. The protective Pt layer is deposited in the FIB to protect the surface oxide from $\mathrm{Ga}^{+}$damage during TEM sample preparation. The thickness of the oxide layer varies from 100 to $400 \mathrm{~nm}$.

In the bulk of the microwire, a characteristic morphology is observed: a nearly straight boundary (indicated by two arrows) around $1 \mu \mathrm{m}$ underneath the oxide layer divides the bulk into two structures. One part (left side of the boundary in Fig. 2a) is predominantly austenite B2, as can be concluded from diffraction shown in Figure 2a (inset). This layer also contains a small fraction of B19' martensite. The other part of the bulk (right side of the boundary) consists of twin structures of B19' as shown in the dark field image in Figure 2b, revealing a characteristic image of layers-within-layers of twin structures. The corresponding diffraction pattern of one of the larger twin variants is shown in Figure $2 b$ (inset), from which a monoclinic angle $\beta=82^{\circ}$ can be measured. As a result, the metallic part of the wire can be characterized as a twinned $\mathrm{B} 19^{\prime}$ martensite core surrounded by a $1 \mu \mathrm{m}$ thick B2 shell.

Figure $2 \mathrm{c}$ is an HRTEM image of the B19' core revealing grains containing several types of twins. For example, compound (001) and (201) twins are recognized from their respective fast Fourier transforms (FFT) and corresponding simulated diffraction patterns, shown in Figure $2 \mathrm{~d}-\mathrm{g}$. Furthermore, due to high residual strain fields in the wire, bent lattice planes are observed as indicated by the white arrowhead in Figure 2c. Also, the two twin-related patterns in Figure $2 \mathrm{e}, \mathrm{g}$ are rotated by a few degrees relative to one another, which again must be attributed to severe deformation. The strong differences in contrast between the inside of the grains and the interfaces in Figure $2 c$ could be an indication of radiation damage from the $\mathrm{Ga}^{+}$ions at the interfaces containing weaker bonds, despite the protective Pt layer.

\section{Oxide Layer}

EDX spectroscopy (EDXS) and EELS reveal that the oxide is predominantly $\mathrm{Ti}$ and $\mathrm{O}$, with a small fraction of $\mathrm{Ni}(<5$ at.\% with strong local variations). The selected area electron diffraction (SAED) pattern of the oxide (Fig. 3a) indicates that it is a combination of small grains of $\mathrm{TiO}$ and $\mathrm{TiO}_{2}$. The interplanar distances for the crystalline phases of $\mathrm{TiO}_{2}$, rutile and anatase, are relatively close (difference below $10 \%)$; hence, it is difficult to determine which phase is in the oxide layer by SAED only showing ill-defined ring patterns from small grains. 


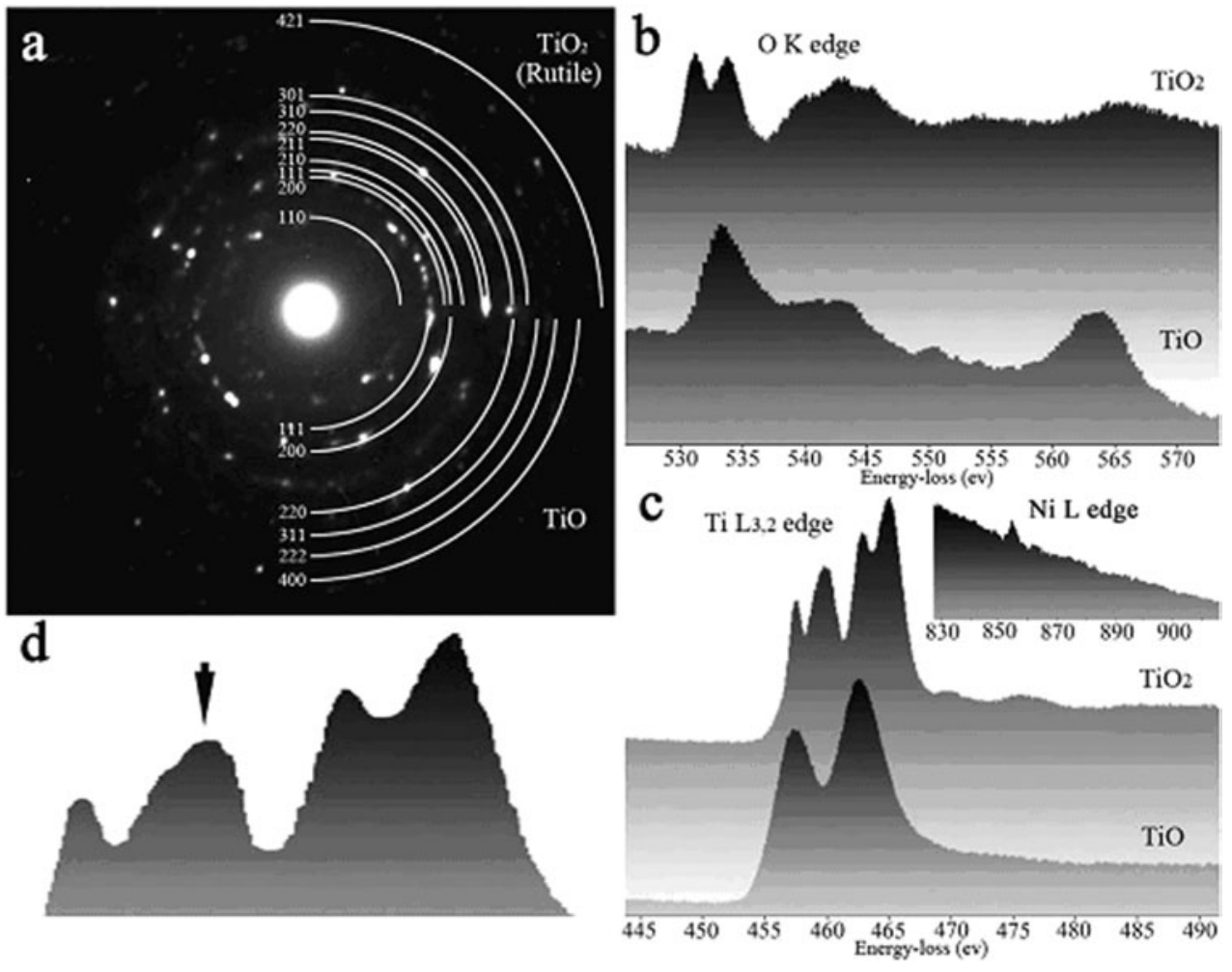

Figure 3. (a) SAED pattern of the oxide layer. Nanoprobe ELNES of (b) $\mathrm{O}$ K and (c) $\mathrm{Ti} \mathrm{L}_{2,3}$ edges as recorded from different nanoscale grains; (d) the partially enlarged $\mathrm{Ti}_{2,3}$ ELNES of $\mathrm{TiO}_{2}$ showing the rutile type.
ELNES of the $\mathrm{O}, \mathrm{Ti}$, and $\mathrm{Ni}$ edges are shown in Figure $3 \mathrm{~b}, \mathrm{c}$. Both profiles of $\mathrm{O} \mathrm{K}$ and $\mathrm{Ti}_{2,3}$ edges in the surface oxide closely resemble those of standard $\mathrm{TiO}$ and $\mathrm{TiO}_{2}$ spectra (Brydson et al., 1989, 1991). Data from different grains reveal the oxide consists of either 51 at.\% Ti, 49 at.\% O ( \pm 2 at.\%), or 33 at.\% Ti, 67 at.\% O ( \pm 3 at.\%), confirming the stoichiometric values for $\mathrm{TiO}$ and $\mathrm{TiO}_{2}$. The inset of Figure $3 \mathrm{c}$ shows the Ni L edge at $854 \mathrm{eV}$, which although too weak for proper quantification, confirms the existence of $\mathrm{Ni}$ in the oxide layer.

As shown before (Potapov \& Schryvers, 2004), the Ti L edges of rutile and anatase are placed at almost the same energy while the onset of $\mathrm{TiO}$ is shifted to a slightly lower energy (by about 0.5 to $2 \mathrm{eV}$ depending on the method chosen for defining the edge onset). Rutile and anatase, however, can only be differentiated in EELS by a small difference in the shape of the second peak of the $\mathrm{Ti}_{3}$ edge (rutile peak leans right, anatase peak leans left) and the O K edge ELNES (Brydson et al., 1991; Potapov et al., 2007). Both the $\mathrm{O} \mathrm{K}$ and $\mathrm{Ti} \mathrm{L}_{2,3}$ ELNES of the $\mathrm{TiO}_{2}$ spectra from this specimen show the rutile signature as shown in Figure $3 \mathrm{~b}, \mathrm{~d}$, respectively, confirming earlier results from conventional wires (Potapov et al., 2007).

\section{Bulk of Nitinol Microwire}

\section{Energy Dispersive X-Ray Spectroscopy}

The content of titanium and nickel may depend on the depth from the surface to the center of the microwire; hence, quantitative EDXS is used to measure the average percentage of titanium and nickel in different depths underneath the oxide layer.

As shown in the cross-sectional TEM image (Fig. 4a), six different depths were analyzed from the bulk. The dashed line indicates the boundary between the B2 shell and $\mathrm{B} 19^{\prime}$ core, as mentioned above. The contrast change across this boundary is caused by changing diffraction conditions. Care was taken to select an area with a constant thickness as determined via the log-ratio method using the zero-loss and plasmon peaks of the corresponding EELS spectrum (Egerton, 1996). A series of five EDX spectra from each depth was measured and the corresponding composition calculated. The average composition and standard deviation for each depth are plotted in Figure 4b.

Quantitative analysis of the EDXS reveals the compositions underneath the B2-B19' boundary, i.e., in the bulk part, are approximately constant ( 50.1 at.\% Ni-49.9 at.\% Ti, \pm 0.2 at.\%), while an increase in $\mathrm{Ni}$ is observed when moving from the boundary toward the surface. The nearsurface areas appear to be enriched in $\mathrm{Ni}$, varying from 50.3 to 51.0 at.\% Ni, as shown in Figure 4 b, be it with a larger standard deviation up to 0.6 at.\% for the outer location. The relatively large standard deviations in the "B2" region are primarily due to the unavoidable inclusion of some remaining B19' grains with a lower Ni content (which also slightly shifts the average to a slightly lower value for $\mathrm{Ni}$ in this area). 

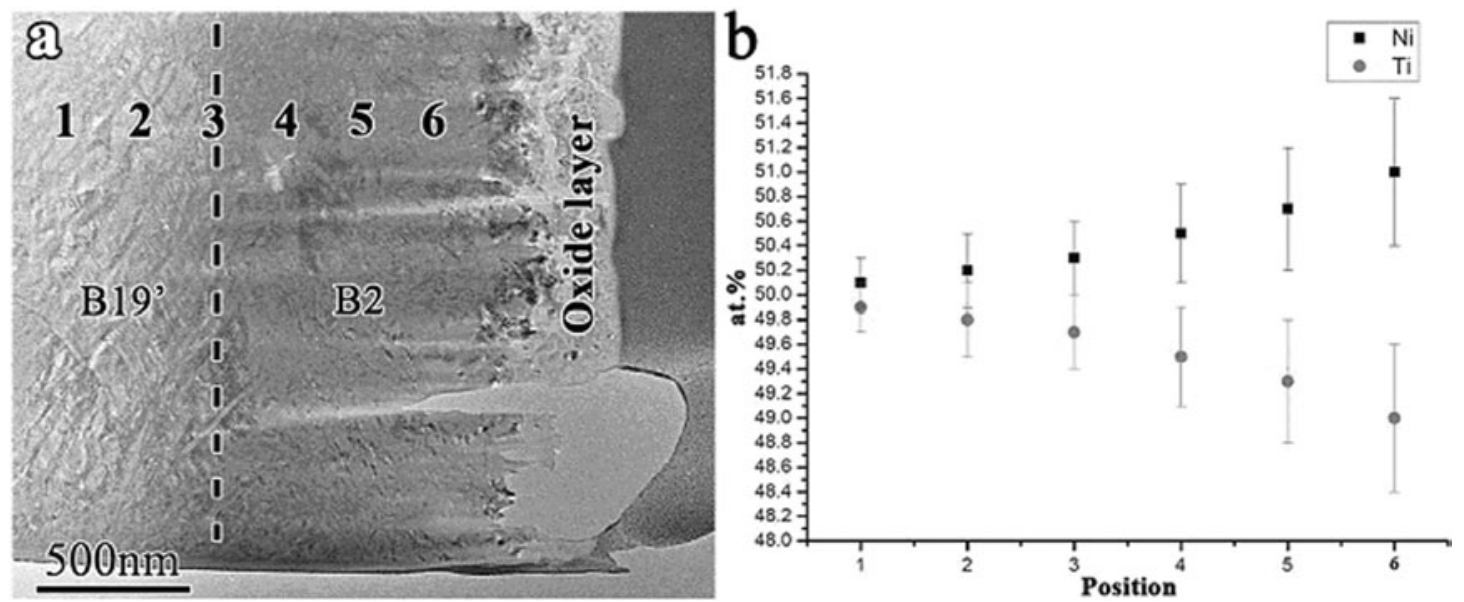

Figure 4. a: TEM image of a cross section of the microwire. b: Schematic of the average Ni and Ti contents at different spot locations in the wire as determined by EDXS.
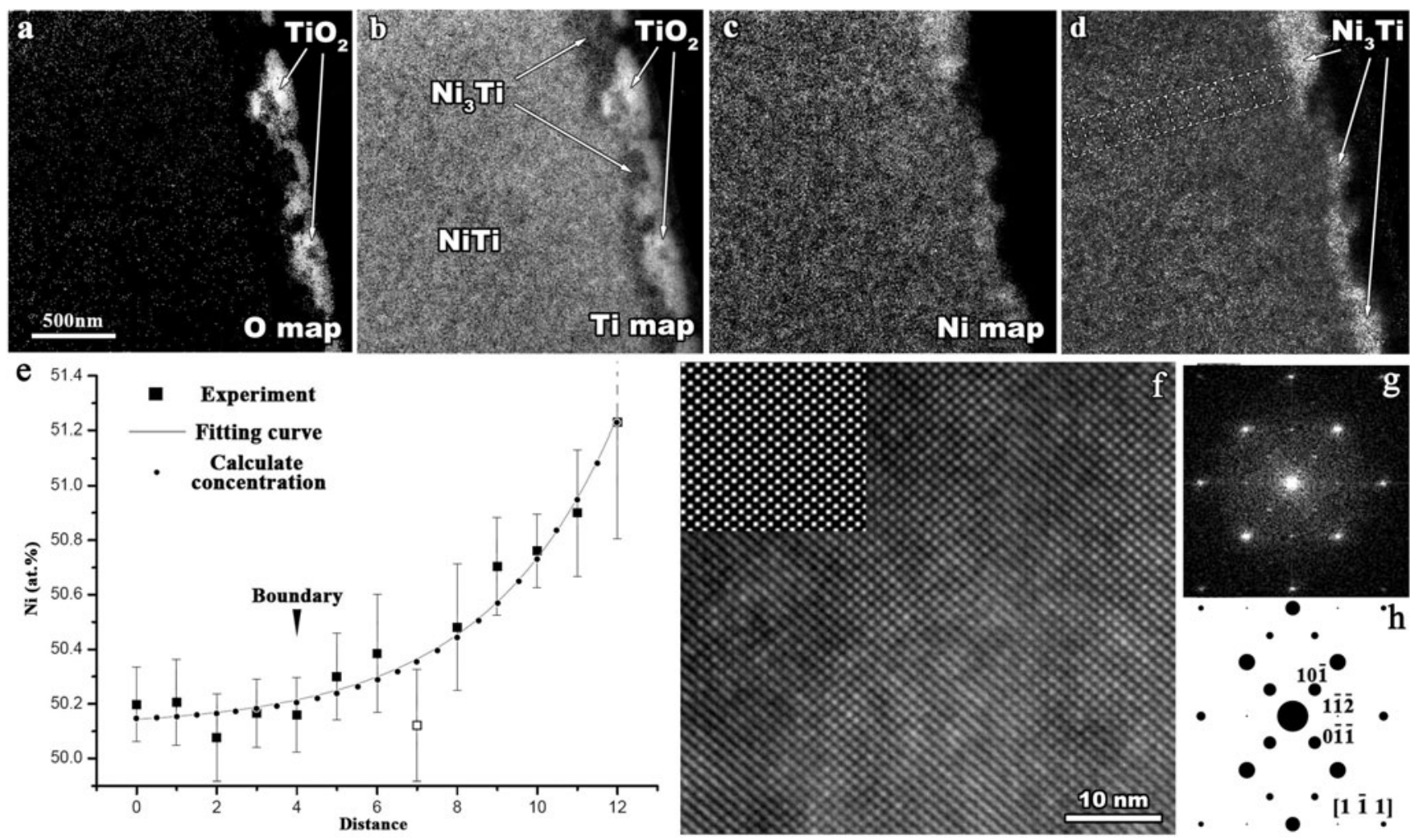

Figure 5. Low-magnification EFTEM elemental maps of (a) O, (b) Ti, and (c) Ni. (d) Ni/Ti ratio map. (e) Averaged Ni content in the Ni-Ti microwire close to the surface as measured from the profile of the Ni/Ti ratio map of $\mathbf{d}$ (filled squares) plus fitted exponential function (small points, equation (1)) (the $\mathrm{Ni}_{3}$ Ti layer starts about $100 \mathrm{~nm}$ further to the right of the last data point). (f) HRTEM image of a $\mathrm{Ni}_{3}$ Ti particle in Ni-rich area including simulated image; (g) FFT of f; (h) simulated diffraction pattern of $\mathrm{Ni}_{3} \mathrm{Ti}[1 \overline{1} 1]$ zone axis.

Electron Energy-Loss Spectroscopy and Energy-Filtered TEM

Energy-filtered TEM (EFTEM) elemental maps shown in Figure $5 \mathrm{a}-\mathrm{c}$ confirm the surface layer is predominantly $\mathrm{Ti}$ and $\mathrm{O}$, and the bulk is predominantly $\mathrm{Ni}$ and $\mathrm{Ti}$. The $\mathrm{Ni} / \mathrm{Ti}$ ratio map obtained from the respective EFTEM maps (Fig. 5d) agrees qualitatively with the EDXS and EELS analysis described above. Figure $5 \mathrm{e}$ shows the profile of the 
averaged $\mathrm{Ni}$ content across the bulk using an averaging rectangle of $125 \times 250 \mathrm{~nm}^{2}$ as indicated in Figure 5d. From this figure it is again seen that the $\mathrm{Ni}$ content increases slowly from the bulk toward the surface. The position of the B2-B19' boundary is indicated by a black arrowhead. Below the boundary, the composition remains approximately constant. The location with the highest amount of Ni measured in this area contains $51.23 \pm 0.42$ at.\% Ni. Here it should be mentioned that the data point with a strong deviation from the other points (indicated by an open square in Fig. 5e) corresponds to a position where a grain of $\mathrm{B} 19^{\prime}$ martensite is observed inside the $\mathrm{B} 2$ shell.

Furthermore, an extra intermediate Ni-rich layer is apparent at the bulk-oxide interface with protrusions clearly matching the discontinuities in the oxide layer, as shown in Figure 5b,d. EDXS indicates that the composition of grains of this layer is close to $\mathrm{Ni}_{3} \mathrm{Ti}(74.1$ at.\% $\mathrm{Ni}$ and 25.9 at.\% Ti, \pm 0.8 at.\%). Figure $5 \mathrm{f}$ shows an HRTEM image of a particle in the Ni-rich area with the FFT shown in Figure 5g. The upper-left corner of Figure $5 f$ shows a simulated HRTEM image (th. $=50 \mathrm{~nm}$, def. $=-40 \mathrm{~nm}$ ) while in Figure $5 \mathrm{~h}$ an electron diffraction pattern is simulated, both obtained using the $\mathrm{Ni}_{3}$ Ti hexagonal unit cell with space group $\mathrm{P}_{3} /$ mmc with $a=0.5096 \mathrm{~nm}$ and $c=0.8304 \mathrm{~nm}$ and fitting the experimental data well.

\section{Discussion}

In the present work, the microstructure of the near surface and interior of a cold-rolled Ni-Ti microwire are investigated by various TEM techniques. As expected, a native, Ti-rich oxide layer is formed during the cold-drawing process yielding a relatively smooth surface, although some cracks in the oxide can be recognized from the SEM images in Figure 1a,b. EELS and ELNES measurements reveal that the oxide contains $\mathrm{TiO}$ as well as $\mathrm{TiO}_{2}$ grains, which can be concluded from elemental ratios and the fine structure of the ionization edges. The latter and HRTEM (not shown here) also indicate that the $\mathrm{TiO}_{2}$ is of the rutile type, which confirms earlier results. In this naturally grown oxide layer, it can be expected that when exposed to atmosphere the first structure that forms is $\mathrm{TiO}$, which is then gradually replaced by the more stable $\mathrm{TiO}_{2}$ (Firstov et al., 2002). Only a very small concentration of $\mathrm{Ni}(<5$ at. $\% \mathrm{Ni}$ and depending on the point of detection) is measured in this layer.

As the starting alloy composition is $\mathrm{Ni}_{49.48} \mathrm{Ti}_{50.52}$, the expected martensitic start temperature is around $65^{\circ} \mathrm{C}$. Hence, we expect the bulk of the wire to be the martensitic phase, as observed, although both analytical methods yield a slightly higher Ni content for the central bulk part. However, the observations also reveal a $1 \mu \mathrm{m}$ austenite B2 shell between the core martensite and the oxide. Although the effects of the cold-rolling should not be neglected, the analytical data show that the formation of the Ti-rich oxide layer leaves a Ni-rich shell in the metal. Because the martensitic transformation start temperature $M_{s}$ is extremely dependent on the composition and decreases with increasing Ni content, $M_{s}$ has dropped below room temperature in the Ni-rich shell. Considering the temperature dependence of $M_{s}$ published by Tang et al. (1999), $M_{s}$ drops below room temperature at $\sim 50.3$ at. $\% \mathrm{Ni}$, which agrees with the measured values of $50.3 \pm 0.3$ at.\% Ni from EDXS and $50.20 \pm$ 0.14 at.\% Ni from EELS. In other words, this phenomenon is clearly reproduced and confirmed by the use of two independent techniques applied to different areas of the sample. Possible artifacts in the EDXS and EELS quantification due to thickness effects have been minimized by using flat areas found via the log-ratio or by using data from $\mathrm{Ni} / \mathrm{Ti}$ ratio maps.

Because it is likely that diffusion plays an important role in the final concentration gradients, an attempt was made to fit an exponential function through the experimental EELS data of the Ni concentration as seen in Figure 5e and shown in equation (1) (with $r_{0}$ being equal to 0 in Fig. 5e):

$$
\begin{gathered}
f(r)=a \cdot \exp \left[\left(r-r_{0}\right) / c\right]+b \\
(a=0.03443, b=50.10, c=429.4) .
\end{gathered}
$$

In between the oxide layer and the bulk, a further $\mathrm{Ni}$ enriched layer is detected by EFTEM. This layer is not a continuous layer and consists of $\mathrm{Ni}_{3}$ Ti particles (space group: hexagonal P6 $6_{3} / \mathrm{mmc}$; lattice parameters: $a=0.5096 \mathrm{~nm}, c=$ $0.8304 \mathrm{~nm}$ ). In some cases, such particles have also been observed inside the oxide layer, where they could explain part of the measured Ni signal, but mostly they are positioned in between the oxide and the bulk. $\mathrm{Ni}_{3} \mathrm{Ti}$ precipitation on the edges of a wire was recently also observed by Zhang et al. on a much larger scale in intentionally oxidized macroscopic Ni-Ti. In that case the $\mathrm{Ni}_{3} \mathrm{Ti}$ phase was precipitated from a eutectic liquid $\mathrm{NiTi}$ to $\mathrm{NiTi}+\mathrm{Ni}_{3} \mathrm{Ti}$, which is caused by the Ni-enrichment due to the selective oxidation of $\mathrm{Ti}$ at high temperatures (Zhang et al., 2007). In that article, however, no $\mathrm{Ni}$ gradient underneath the $\mathrm{Ni}_{3} \mathrm{Ti}$ region was measured.

Based on the above results, it should be possible to correlate the thickness of the Ti-depleted region, the $\mathrm{Ni}_{3} \mathrm{Ti}$ layer and the oxide layer, in a similar way as was done for the Ni-depleted region in the matrix around $\mathrm{Ni}_{4} \mathrm{Ti}_{3}$ precipitates in annealed Ni-Ti bulk material (Yang et al., 2005). In equation (2), using cylindrical coordinates with $r$ the radial distance from the center of the microwire to the surface, $C(r)$ the concentration, $\rho(r)$ the atom density per unit volume, and $L_{0}$ the unit length along the axis of the microwire, the concentration balance $\sum_{i=1,2,3} \mathrm{Ni} \cong \sum_{i=1,2,3} \mathrm{Ti}$ is expressed assuming a 50:50 ratio for $\mathrm{Ni}$ and Ti. In this expression part I $(i=1)$ corresponds to the Ti depleted layer, part II $(i=2)$ corresponds to the $\mathrm{Ni}_{3} \mathrm{Ti}$ layer, and part III $(i=3)$ to the oxide layer, respectively (with an assumed 
zero concentration of $\mathrm{Ni}$ for simplicity because only very little $\mathrm{Ni}$ is found in the oxide layer). In the last part, $R(r)$ is the ratio $\mathrm{TiO} / \mathrm{TiO}_{2}$ in the oxide layer.

Thus,

$$
\begin{aligned}
& \sum_{i=1,2,3} \int_{i} C_{\mathrm{Ni}}(r) \cdot \rho_{i}(r) \cdot 2 \pi r \cdot L_{0} \cdot d r \\
& \cong \sum_{i=1,2,3} \int_{i} C_{\mathrm{Ti}}(r) \cdot \rho_{i}(r) \cdot 2 \pi r \cdot L_{0} \cdot d r
\end{aligned}
$$

Part I: $C_{\mathrm{Ni}}(r)=f(r) ; C_{\mathrm{Ti}}(r)=1-f(r), i=1$,

Part II: $C_{\mathrm{Ni}}(r)=\frac{3}{4} ; C_{\mathrm{Ti}}(r)=\frac{1}{4}, i=2$,

Part III: $C_{\mathrm{Ni}}(r)=0 ; C_{\mathrm{Ti}}(r)=\frac{1}{2} R(r)+\frac{1}{3}[1-R(r)], i=3$.

Part I is fully determined as seen from equation (1), so the balance remains to be determined between the oxide and $\mathrm{Ni}_{3}$ Ti layers. Assuming an average oxide thickness of $200 \mathrm{~nm}$, the amount of Ti missing in the Ti depleted metallic shell only accounts for up to $8 \%$ of the $\mathrm{Ti}$ appearing in the oxide layer. In other words, the Ni-rich $\mathrm{Ni}_{3}$ Ti layer is an inevitable feature for the present wires showing a Ti-oxide layer a few hundred nanometers thick. The actual thickness of the $\mathrm{Ni}_{3} \mathrm{Ti}$ layer of course depends on this oxide thickness and the TiO/ $\mathrm{TiO}_{2}$ ratio $(R(r))$. In practice, the thickness of the $\mathrm{Ni}_{3} \mathrm{Ti}$ layer will be between $120 \mathrm{~nm}$ for a $200 \mathrm{~nm}$ oxide layer containing $100 \% \mathrm{TiO}$ and $550 \mathrm{~nm}$ for a $200 \mathrm{~nm}$ oxide layer containing $100 \% \mathrm{TiO}_{2}$, i.e., values in the range of the particle size observed in Figure 5a,b. Moreover, it can be expected that the size variation of the particles in the intermetallic $\mathrm{Ni}_{3} \mathrm{Ti}$ layer will be due to the level of oxidation in the surface immediately above the respective grains.

Furthermore, the profile of $\mathrm{Ni}$ concentration shown in Figure $5 \mathrm{e}$ can be related to a partial erfc-like profile starting at the bottom end of the $\mathrm{Ni}_{3} \mathrm{Ti}$ layer. The $\mathrm{Ni}$ concentration variation in Part I can indeed be considered as the result of diffusion of remaining excess $\mathrm{Ni}$ atoms from the intermetallic $\mathrm{Ni}_{3} \mathrm{Ti}$ layer into the bulk, at least at those places where the $\mathrm{Ni}_{3} \mathrm{Ti}$ layer is continuous. The concentration distribution $C$ can be described as a function of time $t$ and position $x$, as shown in equation (3):

$$
\begin{aligned}
& C(x, t)=C_{0}+\left(C_{s}-C_{0}\right)\left[1-\operatorname{erf}\left(\frac{x}{2 \sqrt{(D t)}}\right)\right], \\
& \operatorname{erf}(\beta)=\frac{2}{\sqrt{\pi}} \int_{0}^{\beta} \exp \left(-\beta^{2}\right) d \beta, \quad \beta=\frac{x}{2 \sqrt{(D t)}},
\end{aligned}
$$

where $\operatorname{erf}(x / 2 \sqrt{(D t)})$ is called the error function of $(x / 2 \sqrt{(D t)}), D$ is the diffusion coefficient in dimensions $\left(\mathrm{m}^{2} \mathrm{~s}^{-1}\right)$ (in this case $D$ is constant, independent of position and concentration but depending on temperature, viscosity, and size of particles (Cahn \& Haasen, 1983)), $C_{s}$ is the $\mathrm{Ni}$ concentration (75.00 at.\%) in the $\mathrm{Ni}_{3} \mathrm{Ti}$ layer, and $C_{0}$ is the $\mathrm{Ni}$ concentration (50.10 at.\%) far away beneath the B2-B19' boundary in the bulk. Because $D$ and $t$ have not been measured during the process of cold working, we select $\beta=$ $x / 2 \sqrt{(D t)}$ as a variable here. The calculated diffusion profile of the Ni concentration in the relevant area is indicated by black points as shown in Figure $5 \mathrm{e}(\mathrm{Ni}$ at.\% between 50.14 and 51.23 at.\%). The calculated result matches both the fitting curve and experimental data well and yields a value for $D t$ equal to $7.43 \times 10^{-9} \mathrm{~cm}^{2}$. Assuming a typical annealing between the steps of the cold-drawing procedure of about 10 to $20 \mathrm{~min}$, this results in a diffusion coefficient $D$ between $1.23 \times 10^{-11}$ and $6.19 \times 10^{-12} \mathrm{~cm}^{2} / \mathrm{s}$ that are of the same order as previous measurements (Bernardini et al., 2003). So, the phenomenon of $\mathrm{Ni}$ concentration variation beneath the $\mathrm{Ni}_{3}$ Ti layer down to the bulk (in Part I) can indeed be explained by $\mathrm{Ni}$ diffusion from $\mathrm{Ni}_{3} \mathrm{Ti}$ layer into the bulk. Moreover, the measured composition of 51.23 at.\% $\mathrm{Ni}$ underneath the $\mathrm{Ni}_{3} \mathrm{Ti}$ layer could possibly be used to estimate the annealing temperature used during intermediate heat treatments. According to the phase diagram (Okamoto \& Massalski, 2000), the two-phase region (B2 $\mathrm{Ni}_{3} \mathrm{Ti}$ ) that is reached at this interface with the present composition implies that a temperature of around $740^{\circ} \mathrm{C}$ was reached during the intermediate heat treatments of the microwire processing. This may provide a method for reverse engineering. In view of the material preparation, however, it should be remarked that the cold-working will introduce a great amount of defects, especially in the near-surface area. During plastic deformation, point defects such as vacancies are created by dislocation interactions (Wintenberger, 1959; Gonzales et al., 1975), and the diffusion can be accelerated from these defects even at intermediate temperatures.

Inside the martensite region, multiple twins are observed. Although a thorough study still has to be performed, it is clear that many different types of twins and other defects exist. Within the single image presented here in Figure $2 c$, three different types of twins are observed, plus severely bent lattice planes. Two compound (001) and (201) twin cases are identified, which are typical deformation twins in Ni-Ti (Otsuka \& Ren, 2005). As a result of the introduction of these compound twins in between the major planar defects running from the lower-left to upperright corner in Figure 2c, no exact orientation relationship, as expected from the symmetry-breaking martensitic transformation, could be determined in this area. In other parts of the sample (not shown), the classic (111) Type I twins of Ni-Ti martensite were observed (Nishida et al., 1995).

The above-described structural features are of great importance for medical applications of these Ni-Ti microwires. The spontaneously grown oxide layer, which can be 
tuned by careful thermal treatments, hinders the release of $\mathrm{Ni}$, although the importance and the exact distribution of the few percent of $\mathrm{Ni}$ inside this layer still has to be determined. Also, it is still not known whether or not the $\mathrm{Ni}_{3} \mathrm{Ti}$ intermediate layer has any effect on the bonding between the oxide layer and the metal. As for the shape memory and superelasticity, although only $2 \%$ of the full diameter is an austenitic shell, differences in stress-strain behavior between the two different regions or local stress concentrations could possibly deteriorate the long-term functional properties of the material, although such predictions are still rather speculative. The heavy cold deformation also seems to have caused a large amount of twins in the B19' martensite. How far those twins hamper or favor the martensitic transformation after cold working is another important question for further study.

\section{CONCLUSIONS}

The microstructure of an as-received Nitinol microwire was investigated by different TEM techniques. Site-specific samples were prepared by FIB. EDXS and EELS reveal that the surface oxide is predominantly $\mathrm{Ti}$ and $\mathrm{O}$ (with less than 5 at.\% inhomogeneously distributed Ni). ELNES and SAED of this layer revealed it is a combination of $\mathrm{TiO}$ and rutile $\mathrm{TiO}_{2}$. Due to the formation of the oxide layer a $1 \mu \mathrm{m}$ thick shell consisting primarily of $\mathrm{B} 2$ is formed. In between the metallic wire and the oxide surface, an interfacial layer containing $\mathrm{Ni}_{3} \mathrm{Ti}$ particles is observed. The maximum $\mathrm{Ni}$ content measured in the bulk but close to the $\mathrm{Ni}_{3} \mathrm{Ti}$ may yield information as to which temperature was employed for annealing, due to the local Ni-enrichment as a consequence of Ti-oxidation. The $30 \%$ cold-work process leading to the micro dimensions of the wire, resulted in bending of lattice planes and twins of the B19' martensite as seen by HRTEM.

\section{ACKNOWLEDGMENTS}

This research work was performed with the support of an FWO project G.0465.05: "The functional properties of shape memory alloys: A fundamental approach" and the MULTIMAT "Multi-scale modeling and characterization for phase transformations in advanced materials," a Marie Curie Research Training Network (MRTN-CT-2004-505226). The authors also like to thank P. Sittner for valid comments.

\section{References}

BAyer, R. \& Roguin, A. (1997). Early and late results of selfexpandable Nitinol stets: Interim report from multicenter $\mathrm{Eu}-$ ropean study. J Interven Cardiol 10, 207-213.
Berger-Gorbet, M., Broxup, B., Rivard, C. \& Yahia, L. (1996). Biocompatibility testing of NiTi screws using immunohistochemistry of section containing metallic implants. J Biomed Mater Res 32, 243-248.

Bernardini, J., Lexcellent, C., Daróczi, L. \& Beke, D.L. (2003). $\mathrm{Ni}$ diffusion in near-equiatomic $\mathrm{Ni}-\mathrm{Ti}$ and $\mathrm{Ni}-\mathrm{Ti}(-\mathrm{Cu})$ alloys. Philosoph Mag 83, 329-338.

Brydson, R., Sauer, H. \& Engel, W. (1991). Probing Materials Chemistry Using ELNES in TMS Annual Meeting, New Orleans, p. 131.

Brydson, R., Sauer, H., Engel, W., Thomas, J.M., Zeiter, E., Kosugi, N. \& Kuroba, H. (1989). Electron-energy loss and X-ray absorption-spectroscopy of rutile and anatase-A test of structural sensitivity. J Phys: Condens Matter 1, 797-812.

Cahn, R.W. \& HaAsen, P. (Eds.) (1983). Physical Metallurgy (3rd revised, enlarged ed., Parts 1 and 2). Amsterdam: North-Holland Physics Publishing.

Cisse, O., Savagodo, O., Wu, M. \& Yahia, L. (2002). Effect of surface treatment of NiTi alloy on its corrosion behavior in Hank's solution. Biomed J Mater Res 61, 339-345.

Clarke, B., Carroll, W., Rochev, Y., Hynes, M., Bradley, D. \& Plumley, D. (2006). Influence of Nitinol wire surface treatment on oxide thickness and composition and its subsequent effect on corrosion resistance and nickel ion release. J Biomed Mater Res 79A, 61-70.

Egerton, R.F. (1996). Electron-Loss Spectroscopy in the Electron Microscope. New York: Plenum/Springer.

Firstov, G.S., Vitchev, R.G., Kumar, H., Blanpain, B. \& Van Humbeeck, J. (2002). Surface oxidation of NiTi shape memory alloy. Biomaterials 23, 4863-4871.

Gonzales, R., Piqueras, J. \& Bru, L.I. (1975). Formation of point-defect clusters during first cycles of copper fatigues. Phys Stat Sol 29, 161-166.

Kobayashi, Y., Honda, Y., Christie, L., Teirsten, P., Bailey, S., Brown, C., Matthews, R., Franco, A., Schwartz, R., Goldberg, S., Popma, J., Yock, P. \& Fitzgerald, P. (2001). Long-term vessel response of self-expending coronary stent: A serial volumetric intravascular ultrasound analysis from the ASSURE trial. J Am College Cardiol 37, 1329-1334.

Kobayashi, S., Ohgoe, Y., Ozeki, K., Sato, K., Sumiya, T. \& Hirakuri, K. (2005). Diamond-like carbon coatings on orthodontic archwires. Diamond Related Mater 14, 1094-1097.

Kujala, S., Pajala, A., Kallioinen, M., Pramila, A., TuukKANEN, J. \& RyHÄNEN, J. (2004). Biocompatibility and strength properties of nitinol shape memory alloy suture in rabbit tendon. Biomaterials 25, 353-358.

Michiardi, A., Aparicio, C., Planell, J. \& Gil, F. (2006). New oxidation treatment of NiTi shape memory alloys to obtain Ni-free surfaces and to improve biocompatibility. J Biomed Mat Res 77B, 249-256.

Nishida, M., Yamauchi, K., Itai, I., Ohgi, H. \& Chiba, A. (1995). High-resolution electron-microscopy studies of twin boundary structures in B19' martensite in the Ti-Ni shape-memory alloy. Acta Metall Mater 43, 1229-1234.

Окамото, H. \& Massalski, T.B. (2000). Impossible and improbable forms of binary phase diagrams. In Desk Handbook: Phase Diagrams for Binary Alloys, Okamoto, H. (Ed.), pp. xxxix-xliii. Materials Park, OH: ASM International.

Otsuka, K. \& Ren, X. (2005). Physical metallurgy of Ti-Ni-based shape memory alloys. Prog Mater Sci 50(5), 511-678. 
Potapov, P.L. \& Schryvers, D. (2004). Measuring the absolute position of EELS ionisation edges in a TEM. Ultramicroscopy 99, 73-85.

Potapov, P.L., Tirry, W., Schryvers, D., Sivel, V.G.M., Wu, M.Y., Aslanidis, D. \& Zandbergen, H. (2007). Cross-section transmission electron microscopy characterization of the nearsurface structure of medical Nitinol superelastic tubing. J Mater Sci: Materials for Medicine 18, 483-492.

Roguin, A., Granadier, E., Linn, S., Markiewicz, W. \& Beyer, R. (1999). Continued expansion of Nitinol self-expandable stent angiographic analysis and 1-year clinical follow-up. Am Heart J 138(2), 326-333.

RyHÄNEN, J. (1999). In Biocompatibility Evaluation of NickelTitanium Shape Memory Metal Alloy. Ph.D. Thesis, Oulu University, Finland.

Ryhänen, J., Niemi, E., Serlo, S., Niemelä, E., Sandvik, P., Pernu, H. \& Salo, T. (1997). Biocompatibility of nickeltitanium metal and its corrosion behaviour in human cell cultures. J Biomed Mater Res 35, 451-457.

Shabalovskaya, S.A. (1996). On the nature of the biocompatibility and on medical applications of NiTi shape memory and superelastic alloys. Bio-Med Mater Eng 6, 267-289.

Shabalovskaya, S.A. (2001). Physicochemical and biological aspects of Nitinol as a biomaterial. Int Mater Rev 46, 233-250.
Shabalovskaya, S.A. (2002). Surface, corrosion and biocompatibility aspects of Nitinol as an implant material. Bio-Med Mater Eng 12, 69-109.

SuI, J. \& CAI, W. (2006). Effect of diamond-like carbon (DLC) on the properties of the NiTi alloys. Diamond Related Mater 15, $1720-1726$.

Takeshita, F., Takata, H., Ayukawa, Y. \& Suetsugu, T. (1997). Histomorphometric analysis of the response of rat tibia to shape memory alloy (Nitinol). Biomaterials 18, 21-25.

Tang, W., Sundman, B., SAndström, R. \& Qiu, C. (1999). New modelling of the B2 phase and its associated martensitic transformation in the Ti-Ni system. Acta Mater 47, 3457-3468.

Wever, D., Velderhuizen, A., Vries, J.D., Busscher, H., Uges, D. \& VAN HoRn, J. (1998). Electrochemical and surface characterization of NiTi alloy. Biomaterials 19, 761-769.

Wintenberger, M. (1959). Elimination des lacunes dans les aluminiums tres purs. Acta Metall 7, 549-555.

YANG, Z.Q., Tirry, W. \& Schryvers, D. (2005). Analytical TEM investigations on concentration gradients surrounding $\mathrm{Ni}_{4} \mathrm{Ti}_{3}$ precipitates in Ni-Ti shape memory material. Scripta Mat 52, 1129-1134.

Zhang, J., Fan, G., Zhou, Y., Ding, X., Otsuka, K., Nakamura, K., Sun, J. \& Ren, X. (2007). Does order-disorder transition exist in near-stoichiometric Ti-Ni shape memory alloys? Acta Mater 55, 2897-2905. 